\title{
FAMÍLIAS PARALELAS
}

\author{
PARALLEL FAMILIES
}

\section{Giselda Maria Fernandes Novaes Hironaka*}

\begin{abstract}
Resumo:
Embora sempre existissem, os múltiplos arranjos familiares se descortinam nos dias atuais, compondo, assim, novo perfil às famílias do século anterior, embasado à Constituição de 1988 que acolheu, por sua vez, os anseios da sociedade no intuito de novos modelos de famílias.

Palavras-chaves: Lei Civil brasileira. Família patriarcal. Família matrimonializada. Famílias paralelas.

Abstract:

Although always existed, different family structures have been currently revealed, that have composed thus a new profile to the families of the previous century, based on the 1988 Constitution, which hosted the expectations of society in order to new family models.
\end{abstract}

Keywords: Brazilian Civil Law. Patriarch family. Family marriage. Parallel families.

Muito já se disse acerca dos múltiplos arranjos familiares - que sempre existiram - mas que se descortinam com mais coragem nos dias atuais.

A família deixou de ser a família patriarcal e matrimonializada que predominou no anterior século e na anterior Lei Civil brasileira. A Constituição da República, em 1988, acolheu os anseios da sociedade, no sentido da multiplicação dos modelos familiares, registrando ao menos três, a família oriunda do casamento, a família oriunda da união estável e a família monoparental.

Ainda assim, embora o avanço constitucionalmente registrado, muitos outros arranjos não foram recepcionados no bojo constitucional, o que leva a crer, a priori, que não pudessem existir - ou que apenas existissem à margem da lei e da proteção legal - outros tipos, outras uniões que também pudessem ser consideradas entidades familiares e, assim, contar com a visibilidade e com a devida tutela legal. Afinal, família é arranjo que se dá espontaneamente no seio da sociedade, tendo por base e fundamento o afeto cultivado entre seus membros. E, como disse Jean Cruet " "nous voyons tous les jours la

\footnotetext{
* Professora Titular do Departamento de Direito Civil da Faculdade de Direito da Universidade de São Paulo. Diretora Nacional da Região Sudeste do Instituto Brasileiro de Direito de Família - IBDFAM. Ex Procuradora Federal. Este artigo é indicado com louvor pelo Editor Antonio Augusto Machado de Campos Neto, desta Revista da Faculdade de Direito.

1 CRUET, Jean. A vida do direito e a inutilidade das leis. Lisboa: Antiga Casa Bertrand-José Bastos e Cia, Livraria Editora, 1908. (Bibliotheca de Philosophia Scientifica), em epígrafe à abertura da obra.
} 
société refaire la loi, on n'a jamais vu la loi refair la société", isto é, "nós vemos, todos os dias, a sociedade refazer a lei; não se vê, jamais, a lei refazer a sociedade".2

Bem assim. E bem por isso, temos observado que a nossa legislação tem se mostrado incapaz de acompanhar a evolução, a velocidade e a complexidade dos mais diversos modelos de núcleo familiares que se apresentam como verdadeiras entidades familiares, embora o não reconhecimento legal. Esta inércia do Poder Legislativo, contudo, tem sido oposta a um proficiente ativismo do Poder Judiciário, cuja atuação eficiente tem estabelecido o liame imprescindível entre as expectativas sociais e o ordenamento jurídico, principalmente para garantir a dignidade dos membros de tais arranjos familiares e o alcance da justiça.

É certo que o reconhecimento de outros arranjos como entidades familiares não tem ocorrido com facilidade, sequer rapidez. Veja-se, por exemplo, que a própria união estável - antigamente denominada concubinato puro - demorou quase seis décadas de avanços jurisprudenciais para que conseguisse, só então, a chancela legislativa, com a Carta Constitucional de 1988 e, depois, com as duas leis da década de 90 que regulamentaram a união estável e os efeitos sucessórios. Pena que o Código Civil em vigor tenha, a esse respeito, retrocedido cerca de vinte anos, ao legislar, em tantas passagens, em desfavor daquele avanço legislativo antes conquistado. Desconheceu, o Código, a princípio da impossibilidade de retrocesso legal, infelizmente. De toda sorte, a união estável entre homem e mulher tem recepção constitucional e é, para todos os efeitos, considerada entidade familiar. Na mesma esteira demorada, sofrida, mas corajosa, está o reconhecimento, pelo Poder Judiciário, do status de entidade familiar que se concedeu, recentemente, às uniões homoafetivas. São conquistas, como já se disse, que não aconteceram de uma hora para outra, mas a trajetória de vanguarda dos Tribunais, abriu a possibilidade de visibilidade e de tutela, pelo Estado, de tais arranjos familiares.

Carlos Eduardo Pianovski Ruzyk ${ }^{3}$ descreveu, quase que exaustivamente, a variedade de configurações familiares paralelas que podem existir (e existem), quer do ponto de vista das relações de parentalidade, quer do ponto de vista das relações de conjugalidade, ${ }^{4}$ a saber, segundo o autor: (i) situação que envolva filhos de pais separados ou divorciados, que mantém os vínculos de afeto e de convivência com ambos os pais; (ii) situação de pessoas divorciadas ou separadas que constituam novas famílias nucleares por meio de um novo casamento ou união estável, mantendo o vínculo afetivo com a

Tradução livre da autora deste artigo.

RUZYK, Pianovski. Familias simultâneas: da unidade codificada à pluralidade constitucional. Rio de Janeiro: Renovar, 2005.

4 Entenda-se, aqui, o sentido lato da expressão conjugalidade, para que ela possa acolher, nesta sua amplitude e flexibilidade, tanto os laços derivados do matrimônio formalizado, como da conformação de situação de fato, isto é, a informal união estável. 
prole resultante da primeira união; (iii) situação de netos que convivam entre o núcleo familiar formado com os seus pais e vínculos de convivência contínua com seus avós, por exemplo; (iv) situação de dois núcleos familiares compostos, ambos, por casamento formal, caso de bigamia típica; (v) pluralidade pública e estável de conjugalidades, como de casamento mais união estável, ou de união estável mais união estável. Estes são alguns dos possíveis arranjos elencados por Pianovski. Mas, certamente, a listagem dos arranjos de parentalidade e de conjugalidade não para por aí; há inúmeras outras formas ou modalidades de estruturas familiares.

No que diz respeito, propriamente, aos modelos familiares de conjugalidades concomitantes, isto é, a famílias conjugais (por casamento ou por união estável) paralelas ou simultâneas, o assunto tem caminhado a passos duros e lentos, com a maioria dos julgados não reconhecendo a possibilidade de tutela concomitante. Mas, aqui e ali, já se apresentam decisões que, corajosamente, já têm chancelado a possibilidade de reconhecimento. Chegaremos lá, num futuro nem tão longínquo, quiçá, quando a jurisprudência se enrobustecerá e o Poder Legislativo - ou o ativismo do Poder Judiciário - entenderem que "a lei não refaz a sociedade, mas que a sociedade refaz a lei!"

"Não é mais o indivíduo que existe para a família e para o casamento, mas a família e o casamento existem para o seu desenvolvimento pessoal, em busca de sua aspiração à felicidade", diz Luiz Edson Fachin. ${ }^{5}$ Sua célebre frase mostra exatamente o caráter eudemonista das famílias da contemporaneidade. Quer dizer, não se inventou agora a ideia de que cada pessoa perseguem, por toda a vida, o seu projeto pessoal de felicidade. E essa busca se dá, na rigorosa maioria das vezes, durante os períodos de convivência familiar, quer pertencendo à sua família original, quer pertencendo à família constituída pelos relacionamentos afetivos mais adultos. Vale dizer, a busca pelo eudemonismo decorre daquela convivência interpessoal marcada pela afetividade e pela solidariedade mútua, e que se estabelece, normalmente, dentro de ambientes considerados familiares, pelas novas visões do que sejam entidades familiares. A perspectiva institucionalizada da família cede espaço e vez para esta realização pessoal de seus membros, fenômeno esse que se convencionou chamar de repersonalização das relações de família. ${ }^{6}$

Para além deste caráter eudemonista que a família contemporânea passou a ter, outras transformações também contribuíram para esta repersonalização das relações familiais. Entre elas agiganta-se a afetividade, que ganhou foro de princípio jurídico na expressão e retrato da família como ela é nos dias atuais. Ao se falar em afeto, já não se

FACHIN, Luiz Edson. Elementos críticos do direito de família: curso de direito civil. Rio de Janeiro: Renovar, 1999. p. 10.

6 LÔBO, Paulo Luiz Netto. A repersonalização das famílias. Revista Brasileira de Direito de Família, Porto Alegre: Síntese, v. 6, n. 24, p. 151, 2007. 
o entende como antes, quer dizer, ao tempo da família patriarcal e hierarquizada, quando então significava apenas um sentimento fragilizado e até mesmo tido como secundário, nas relações de família. Hoje, o afeto - considerado como valor jurídico - promoveu a família de um status patriarcal para um status nuclear. Se, no anterior tempo, o afeto "era presumido em razão de o vínculo jurídico dar a existência de uma família", no espaço atual "ele é um dos elementos responsáveis pela visibilidade e continuidade das relações familiais".?

Se juntarmos apenas estes dois fenômenos que matizam a família constitucionalizada, na contemporaneidade, chegaremos, é provável, a uma fórmula que nos dirá que a família se idealiza e se constrói por meio de uma entidade que se alicerça na afetividade e que tem, como causa final, a busca do projeto pessoal de felicidade de cada um de seus membros. Com este espelho, o diagnóstico para a verificação se determinado relacionamento interpessoal pode ser considerado família, fica muito fácil, afinal de contas. Caso o relacionamento em questão seja relativo à conjugalidade - como é a hipótese central deste estudo - a afetividade e a busca da felicidade o moldam de modo a que se o possa considerar como verdadeira entidade familiar, conforme descrição constitucional.

Assim consideradas as entidades familiares, simples seria a conclusão acerca licitude da simultaneidade conjugal, situação em que concorreriam, em igualdade de condições, ambos os núcleos, relativamente a direitos e deveres daí derivados. Mas a verdade é que tanto a doutrina, quanto a jurisprudência, têm se dividido quanto a considerar lícita ou ilícita esta simultaneidade de relacionamentos familiais. Pessoalmente considero a possibilidade de se concluir pela licitude da simultaneidade dos relacionamentos, com consequências jurídicas e protetivas, em muitos dos casos.

$\mathrm{O}$ que, segundo o meu sentir, tem basicamente produzido esta divergência doutrinária e, por consequência, jurisprudencial, é o fato de se considerar a monogamia como princípio, ou como regra do direito de família, bem como do fato de se utilizar, na hipótese de aplicação de princípios, da técnica da ponderação principiológica.

Desta forma, Rodrigo da Cunha Pereira ${ }^{8}$ entende que a monogamia é, sim, princípio orientador das relações familiares, atuando como um ponto-chave das conexões morais das relações amorosas e conjugais, advertindo que não se trata simplesmente de uma norma moral ou moralizante. Um pouco mais adiante, o autor registra que o seu negativo, ou o avesso deste princípio, não significa necessariamente o horror de toda a organização social, ou seja, a promiscuidade. Traição e infidelidade não significam

CARBONERA, Silvana Maria. O papel jurídico do afeto nas relações de família. In: FACHIN, Luiz Edson (Coord.). Repensando fundamentos de direito civil contemporâneo. Rio de Janeiro: Renovar, 1998. p. 309.

8 PEREIRA, Rodrigo da Cunha. Princípios fundamentais norteadores do direito de família. São Paulo: Ed. Saraiva, 2012. p. 127. 
necessariamente a quebra do sistema monogâmico. ${ }^{9} \mathrm{E}$ assim analisando o fenômeno da infidelidade e a suas consequências no rompimento da monogamia, Rodrigo da Cunha Pereira, assenta seu pensamento no sentido de só se considerar a ideia da ruptura da monogamia se, por acaso, a relação extraconjugal resultar na constituição de uma família que venha correr em paralelo com aquela outra família anteriormente constituída. ${ }^{10} \mathrm{Em}$ momento um pouco mais adiantado, ainda, da obra neste parágrafo referida, o autor abrindo um subtítulo denominado o justo e o legal na monogamia - contempla a hipótese, então, da existência de uma outra família que teria sido formada a partir da quebra do princípio da monogamia. E escreve: Em contrapartida, aquela outra família, paralela ao casamento ou à união estável, foi constituída de fato. Tornou-se uma realidade jurídica. Prossegue deixando a pergunta que se recusa calar: Como é possível conciliar o justo e o legal, ou seja, como compatibilizar o princípio da monogamia com essas situações fáticas $?^{11} \mathrm{O}$ autor, assim, embora defenda que a monogamia seja princípio constitucional orientador das relações de conjugalidade, acaba por demonstrar seu real interesse em não desviar os olhos da realidade da vida. Bem por isso, adiante em sua obra, quando faz a distinção entre concubinato adulterino e não adulterino (considerando este último como união estável, que efetivamente é), levanta circunstância da vida extremamente comum de acontecer, e diz: Da mesma forma, constitui uma união estável (g.n.) se uma das partes é casada, mas aquele casamento é mera reminiscência cartorial, seja porque já há uma separação de fato, ou mesmo não tendo uma separação de fato, o casamento é de mera aparência. ${ }^{12}$ Adiante, ainda, Rodrigo da Cunha Pereira marca com firmeza sua posição, mesmo considerando a monogamia como princípio jurídico: ... se o fato de ferir este princípio [o da monogamia] significar fazer injustiça, devemos recorrer a um valor maior, que é o da prevalência da ética sobre a moral, para que possamos [nos] aproximar do ideal de justiça. O raciocínio, então, exige que os princípios sejam aplicados ponderadamente, ${ }^{13}$ sobrepondo-se o maior e mais ético àquele outro, mesmo que, a priori, este tenha se oferecido como princípio norteador. Fica o registro do pensamento do autor, exímio advogado e presidente nacional do Instituto Brasileiro de Direito de Família.

Por outro lado, há autores, como Maria Berenice Dias, ${ }^{14}$ que entendem que a monogamia constitui tão apenas uma regra de orientação, ainda que deva se coadunar

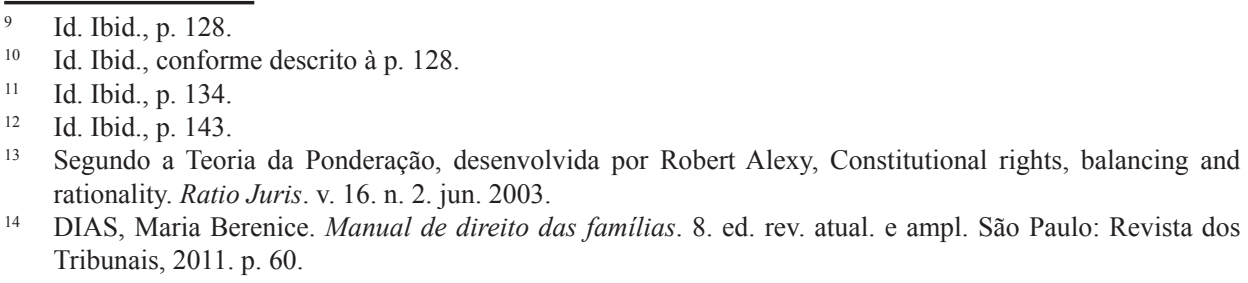

14 DIAS, Maria Berenice. Manual de direito das famílias. 8. ed. rev. atual. e ampl. São Paulo: Revista dos Tribunais, 2011. p. 60. 
com os princípios fundamentais da República. Esta autora, citando Carlos Eduardo Pianovski Ruzyk, assim escreve: "Não se trata [a monogamia] de um princípio estatal de família, mas sim de uma regra restrita à proibição de múltiplas relações matrimonializadas, constituídas sob a chancela do Estado. E completa: Ainda que a lei recrimine, de diversas formas, quem descumpre o dever de fidelidade, não há como considerar a monogamia como princípio constitucional, até porque a Constituição não a contempla. Seu raciocínio estende-se à seguinte comparação: Ao contrário, tanto [a Constituição] tolera a traição que não permite que os filhos se sujeitem a qualquer discriminação, mesmo quando se tratar de prole nascida de relações adulterinas ou incestuosas". ${ }^{15} \mathrm{E}$ a autora arremata seu pensamento revelando a função ordenadora da monografia, não a elevando, portanto, ao status de princípio ordenador.

Infelizmente, a tendência jurisprudencial, nos dias atuais, ainda é muito conservadora (senão preconceituosa), não admitindo, pois, a geração de efeitos jurídicos às relações conjugais simultâneas. Mas, por outro lado, avolumam-se, já, também os julgados a favor do reconhecimento e tutela das situações marcadas pela simultaneidade conjugal, julgados estes mormente oriundos do TJRS (mas não só dele), o que produz, mesmo que de forma ainda incipiente, o alento da conformação da justiça, segundo o meu sentir e expectativa. Neste sentido, por exemplo, manifesta-se Letícia Ferrarini, ${ }^{16}$ quando afirma que "as famílias em situação de simultaneidade a partir do protagonista conjugal são estigmatizadas. A ideia presente ainda hoje é no sentido de conceber essas relações como estritamente adulterinas e, como tal, são todas generalizadas, consideradas como iguais, e, portanto, ignoradas nas suas peculiaridades". Prossegue, adiante: "no imaginário social ainda prepondera a ideia de que as relações paralelas ao casamento se caracterizam pelo triângulo amoroso formado pelo mito, no qual a esposa é santificada, o marido é vitimizado e "a outra", por conseguinte, é satanizada".

Desejo tomar como minhas as palavras da referida autora ${ }^{17}$ quando, colhem a lição de Carlos Maximiliano (Hermenêutica e aplicação do direito), e descreve sua enfática preocupação de evitar não apenas o demasiado apego à "letra fria da lei", como também o excesso contrário, de forçar determinada exegese. Tudo deve ser medido à face da situação real, caso a caso, mas tendo como referencial mensurável, especialmente a afetividade, além dos demais requisitos que ajudam compor a entidade familiar que se denomina união estável. Nesse sentido, o registro de Marianna Chaves, ${ }^{18}$ a partir de

15 Id. Ibid., p. 60.

16 FERRARINI, Letícia. Famílias simultâneas e seus efeitos jurídicos: pedaços da realidade em busca da dignidade. Porto Alegre: Livraria do Advogado, 2010. p. 89 e ss.

17 Id. Ibid., p. 80.

18 CHAVES, Marianna. Famílias paralelas. Publicado no Portal do IBDFAM. Disponível em: < http://www. ibdfam.org.br/?artigos\&artigo=495>. Acesso em: 30 dez. 2011. 
afirmação de Rodrigo da Cunha Pereira: ${ }^{19}$ "se existe amor, convivência e assistência recíproca, desvelo, não deve o sistema jurídico deixar de lado estes fatos, apenas porque presente o papel formalizador de um casamento. Destarte, iníqua seria uma proteção do Estado a uma família que há tempos não existe, onde a comunhão de vida há muito se dissipou e que, atualmente, é apenas uma anamnese cartorial, em menoscabo de uma legítima, atual e genuína relação familiar, fundada no afeto". Thiago Felipe Vargas Simões, ${ }^{20}$ lembrando a interessantíssima concepção do que se convencionou denominar de estado de família - concepção esta atribuída ao argentino Guilhermo Antonio Borda ${ }^{21}$ - escreve que este estado de família se resume na posição que uma pessoa ocupa dentro de um núcleo familiar. E prossegue o articulista dizendo que se trata da família lastreada na cooperação, respeito, cuidado, amizade, carinho, afinidade, atenção recíproca entre todos os seus membros.

Após todas estas revisões, encerro estas minhas breves considerações acerca dos reflexos jurídicos nas relações familiais simultâneas, buscando retratar, ainda que superficialmente, conforme o tempo, neste conclave, exige, o momento presente a respeito do importantíssimo assunto, assunto da atualidade da vida dos homens, hoje com maior visibilidade do que já esteve, antes, no tempo em que se ignorava juridicamente tais relacionamentos, jogando-os "para baixo dos tapetes", de resto como tantas outras situações e circunstâncias da vida como ela efetivamente é. Que o direito não permaneça alheio à realidade humana, à realidade das situações existentes, às mudanças sociais importantes que, sem dúvida, têm se multiplicado na história das famílias, exatamente como ela é. Cerrar os olhos, talvez seja mais um dos inúmeros momentos de hipocrisia que o Legislativo e o Judiciário têm repetido deixar acontecer, numa era em que já não mais se coaduna com as histórias guardadas a sete chaves.

Iniciei, mas também desejo encerrar, estas minhas considerações, citando Jean Cruet, que tanto me impressiona quando abre sua importante e clássica obra "A vida do Direito e a inutilidade das leis", afirmando, com toda e absoluta razão: "nous voyons tous les jours la société refaire la loi, on n'a jamais vu la loi refair la société".

Abaixo segue um rol de julgados acerca do assunto, oriundos de Tribunais estaduais e também das Cortes mais altas, divididas em duas colunas, favoráveis e desfavoráveis. A leitura cuidadosa das razões dos julgadores é capaz, por si só, de nos dizer a época de transição pela qual o Direito passa a respeito do assunto famílias paralelas.

19 PEREIRA, Rodrigo da Cunha. Concubinato e união estável. 7166 ed. revista e atualizada. Belo Horizonte: Del Rey, 2004. p. 70-71.

20 SIMÕES, Thiago Felipe Vargas. A família afetiva: o afeto como formador de família. Publicado no Portal do IBDFAM: Disponível em: <http://www.ibdfam.org.br/?artigos\&artigo=336>. Acesso em: 30 dez. 2011.

21 BORDA, Guilhermo Antonio. Manual de familia. 12. ed. Buenos Aires: Abeledo Perrot, 2002. 
A passagem da rejeição para a da aceitação, mormente em sede de Direito de Família, é sempre muito lenta, mas é possível enxergar luz no final do túnel, por certo.

União estável concomitantemente ao casamento ou a outra união estável

$$
\text { Ilustração comparativa }
$$

\section{TRIBUNAL: TJRS}

Favorável: APELAÇÃO. UNIÃO ESTÁVEL PARALELA AO CASAMENTO DE PAPEL. ARTIGO 1.727 DO CÓDIGO CIVIL DE 2002. EFEITOS.

Interpretação do Código Civil de 2002 com eticidade, socialidade e operabilidade, como ensina Miguel Reale.

Reconhecimento de efeitos a união estável paralela ao casamento de papel, como medida que visa evitar o enriquecimento ilícito.

DERAM PARCIAL PROVIMENTO.

(TJRS, Apelação Cível no 70014248603, Rel. Des. Rui Portanova, j. 27/04/2006)

Desfavorável: EMENTA: APELAÇÃO CÍVEL. UNIÃO ESTÁVEL. AUSÊNCIA DE PROVA DOS REQUISITOS INDISPENSÁVEIS Á CARACTERIZAÇÃO DA UNIÃO ESTÁVEL. COMPANHEIRO CASADO. IMPEDIMENTO PARA CONFIGURAÇÃO DA UNIÃO ESTÁVEL. O reconhecimento da união estável depende de prova plena e convincente de que o relacionamento se assemelha, em tudo e perante todos, ao casamento. A existência de relação amorosa entre as partes, sem os requisitos exigidos pela lei, não se caracteriza como união estável. Ausência de prova da coabitação, continuidade, publicidade e objetivo de constituir família, ônus que incumbia à autora. Impossibilidade de reconhecimento de união estável concomitante ao casamento, quando não evidenciada a separação de fato de um dos concubinos. APELAÇÃO PROVIDA. (SEGREDO DE JUSTIÇA).

(TJRS, Apelação Cível No 70027944925, Sétima Câmara Cível, Tribunal de Justiça do RS, Relator: André Luiz Planella Villarinho, Julgado em 16/09/2009).

\section{TRIBUNAL: TJRS}

Favorável: UNIÃO ESTÁVEL. RECONHECIMENTO. COMPANHEIRO FALECIDO. SEPARAÇÃO DE FATO. PROVA. INEXISTÊNCIA DE 
CONCUBINATO. 1. Para o reconhecimento da união estável não é necessário que as partes estejam divorciadas ou separadas judicialmente, bastando que estejam separadas de fato. Inteligência do art. $1.723, \S 1^{\circ}$, do CCB. 2. Os efeitos da relação não decorrem do estado civil das partes, mas do vínculo afetivo e da natureza da relação, que deve ser duradoura, pública e contínua, com o propósito de constituir uma família. 3. Comprovada a notoriedade e a publicidade, assim como a affectio maritalis, imperioso é o reconhecimento da união estável havida entre a autora e o de cujus. Recurso desprovido.

(Apelação Cível No 70015261407, Sétima Câmara Cível, Tribunal de Justiça do RS, Relator: Sérgio Fernando de Vasconcellos Chaves, Julgado em 02/08/2006).

\section{TRIBUNAL: TJRS}

Favorável: APELAÇÃO CÍVEL. UNIÃO ESTÁVEL. RELACIONAMENTO PARALELO AO CASAMENTO.

Se mesmo não estando separado de fato da esposa, vivia o falecido em união estável com a autora/companheira, entidade familiar perfeitamente caracterizada nos autos, deve ser mantida a procedência da ação que reconheceu a sua existência, paralela ao casamento. A esposa, contudo, tem direito sobre parcela dos bens adquiridos durante a vigência da união estável.

RECURSO ADESIVO. Os honorários advocatícios em favor do patrono da autora devem ser fixados em valor que compensa dignamente o combativo trabalho apresentado. Apelação dos réus parcialmente provida. Recurso adesivo da autora provido.

(TJRS, Apelação Cível no 70015693476, Rel. Des. José S. Trindade, J. 20/07/2006).

Desfavorável: EMENTA: UNIÃO ESTÁVEL. PRESSUPOSTOS. AFFECTIO MARITALIS. COABITAÇÃO. PUBLICIDADE DA RELAÇÃO. PRINCÍPIO DA MONOGOMIA. 1. Não constitui união estável o relacionamento entretido sem a intenção clara de constituir um núcleo familiar. 2. A união estável assemelha-se a um casamento de fato e indica uma comunhão de vida e de interesses, reclamando não apenas publicidade e estabilidade, mas, sobretudo, um nítido caráter familiar, evidenciado pela affectio maritalis. 3 . Não comprovada a publicidade do relacionamento marital e da comunhão de vida com a autora e ausente 
prova cabal da separação de fato com a esposa, a improcedência da ação se impõe, pois não é permitido no nosso ordenamento jurídico a existência de união estável paralela ao casamento. Recurso desprovido. (TJRS, Apelação Cível No 70029767290, Sétima Câmara Cível, Tribunal de Justiça do RS, Relator: Sérgio Fernando de Vasconcellos Chaves, Julgado em 16/12/2009).

\section{TRIBUNAL: TJRS}

Favorável: APELAÇÃO. UNIÃO ESTÁVEL CONCOMITANTE AO CASAMENTO. POSSIBILIDADE. DIVISÃO DE BEM. "TRIAÇÃO”. VIÁVEL O RECONHECIMENTO DE UNIÃO ESTÁVEL PARALELA AO CASAMENTO. PRECEDENTES JURISPRUDENCIAIS Caso em que a prova dos autos é robusta em demonstrar que a apelante manteve união estável com o falecido, mesmo antes dele se separar de fato da esposa. Necessidade de dividir o único bem adquirido no período em que o casamento foi concomitante à união estável em três partes. "Triação". Precedentes jurisprudenciais. DERAM PROVIMENTO, POR MAIORIA.

(TJRS, Apelação Cível no 70024804015, Rel. Des. Rui Porta Nova, j 13/08/2009)

Desfavorável: EMENTA: APELAÇÃO CÍVEL. UNIÃO ESTÁVEL PARALELA AO CASAMENTO. NÃO CARACTERIZAÇÃO. IMPROCEDÊNCIA. Em pleno vigor o casamento do alegado companheiro até o seu falecimento, era ônus da autora demonstrar que o relacionamento mantido com ele, paralelo ao casamento dele, se revestiu das características de uma verdadeira união estável. Não caracterizada a entidade familiar, mas sim um relacionamento extraconjugal, mantém-se a improcedência da ação. Apelação desprovida. (SEGREDO DE JUSTIÇA) (TJRS, Apelação Cível $N^{o} 70029087228$, Oitava Câmara Cível, Tribunal de Justiça do RS, Relator: José Ataídes Siqueira Trindade, Julgado em 07/05/2009).

\section{TRIBUNAL: TJRS}

Favorável: EMENTA: EMBARGOS INFRINGENTES. UNIÃO ESTÁVEL PARALELA AO CASAMENTO. RECONHECIMENTO. Ainda que o falecido não tenha se separado de fato e nem formalmente da esposa, existindo a convivência pública, contínua, duradoura e o objetivo de constituir família com a companheira, há que se reconhecer a existência 
da união estável paralela ao casamento. O aparente óbice legal representado pelo $\S 1^{\circ}$ do art. 1723 do Código Civil fica superado diante dos princípios fundamentais consagrados pela Constituição Federal de 1988, principalmente os da dignidade e da igualdade. EMBARGOS INFRINGENTES DESACOLHIDOS, POR MAIORIA. (SEGREDO DE JUSTIÇA)

(TJRS, Embargos Infringentes $N^{o}$ 70020816831, Quarto Grupo de Câmaras Cíveis, Tribunal de Justiça do RS, Relator Vencido: Ruy Ruben Ruschel, Redator para Acordão: José Ataídes Siqueira Trindade, Julgado em 14/09/2007).

Desfavorável: EMENTA: UNIÃO ESTÁVEL. PRESSUPOSTOS. AFFECTIO MARITALIS. COABITAÇÃO. PUBLICIDADE DA RELAÇÃO. PRINCÍPIO DA MONOGOMIA. 1. Não constitui união estável o relacionamento entretido sem a intenção clara de constituir um núcleo familiar. 2. A união estável assemelha-se a um casamento de fato e indica uma comunhão de vida e de interesses, reclamando não apenas publicidade e estabilidade, mas, sobretudo, um nítido caráter familiar, evidenciado pela affectio maritalis. 3. Não comprovada a publicidade do relacionamento e ausente prova cabal da coabitação e da comunhão de vidas, a improcedência da ação se impõe, pois não é permitida no nosso ordenamento jurídico a existência de uma união estável paralela ao casamento. Recurso desprovido. (SEGREDO DE JUSTIÇA)

(TJRS, Apelação Cível $N^{o}$ 70029141900, Sétima Câmara Cível, Tribunal de Justiça do RS, Relator: Sérgio Fernando de Vasconcellos Chaves, Julgado em 11/11/2009).

\section{TRIBUNAL: TJRS}

Favorável: APELAÇÃO CÍVEL. AÇÕES DECLARATÓRIAS CONEXAS RELATIVAS A UNIÕES ESTÁVEIS SIMULTÂNEAS. COMPANHEIRO FALECIDO. Evidenciado, a partir do conjunto probatório, que ambas as autoras mantiveram união estável com o de cujos, inclusive com prole e com todos os contornos que lhe são peculiares $i$ convivência pública, contínua e duradoura e estabelecida com o objetivo de constituição de família ¿ a procedência das duas demandas mostrase inafastável, impondo-se, pois, reconhecer a existência de relações paralelas caracterizando ambas união estável, como definido em lei.

NEGARAM PROVIMENTO A TODOS OS RECURSOS. 
(Apelação Cível No 70024427676, Oitava Câmara Cível, Tribunal de Justiça do RS, Relator: Alzir Felippe Schmitz, Julgado em 16/10/2008).

\section{TRIBUNAL: TJRS}

Favorável: APELAÇÃO CÍVEL. AÇÃO DECLARATÓRIA DE UNIÃO ESTÁVEL PARALELA AO CASAMENTO. SITUAÇÃO EXCEPCIONAL QUE AUTORIZA O RECONHECIMENTO. SENTENÇA QUE MERECE MANTIDA. AGRAVO RETIDO DESPROVIDO. PEDIDO DA AUTORA PARA SER NOMEADA COMO ADMINISTRADORA DOS BENS DO ESPÓLIO. DESCABIMENTO NO CASO CONCRETO. O PEDIDO DA AUTORA ENVOLVE QUESTÕES QUE DEVEM SER LEVANTADAS, DISCUTIDAS E DECIDIDAS NOS AUTOS DO INVENTÁRIO DOS BENS DEIXADOS PELO FALECIDO. Demonstrado que, mesmo não estando separado de fato da esposa, o falecido viveu por mais de cinqüenta anos em união afetiva com a autora, resta configurada a união estável paralela ao matrimônio, com todos os requisitos legais pertinentes. Agravo retido e Recurso de apelação desprovidos.

(TJRS, Apelação Cível no 70028251171, Rel Des. Ricardo Raupp Ruschel, j. 14/10/2009)

\section{TRIBUNAL: TJRS}

Favorável: $\quad$ APELAÇÃO CÍVEL. AÇÃO DECLARATÓRIA DE UNIÃO ESTÁVEL PARALELA AO CASAMENTO. Demonstrada a configuração da união estável paralela ao matrimônio, com todos os requisitos legais pertinentes, deve ser reconhecida e declarada a sua existência, conforme precedentes da Corte. PARTILHA. IMÓVEL ADQUIRIDO COM VALORES PROVENIENTES DE SAQUE DO FGTS. O saque da conta de FGTS para a compra de imóvel afasta a incomunicabilidade defendida pelo recorrente. AJG. Demonstrada a insuficiência de recursos para arcar com as despesas do processo sem prejuízo do próprio sustento, deve ser concedido o benefício da AJG.

DERAM PARCIAL PROVIMENTO AO APELO.

(Apelação Cível No 70030384820, Oitava Câmara Cível, Tribunal de Justiça do RS, Relator: Alzir Felippe Schmitz, Julgado em 20/08/2009).

\section{TRIBUNAL: TJRS}

Favorável: $\quad[\ldots]$ Viável reconhecer união estável paralela ao casamento. Precedentes 
jurisprudenciais. Caso em que restou cabalmente demonstrada a existência de união estável entre as partes, consubstanciada em contrato particular assinado pelos companheiros e por 03 testemunhas; e ratificada pela existência de filho comum, por inúmeras fotografias do casal junto ao longo dos anos, por bilhetes e mensagens trocadas, por existência de patrimônio e conta-bancária conjunta, tudo a demonstrar relação pública, contínua e duradoura, com claro e inequívoco intento de constituir família e vida em comum. Reconhecimento de união dúplice que impõe partilha de bens na forma de "triação", em sede de liquidação de sentença, com a participação obrigatória da esposa formal. Precedentes jurisprudenciais. Ex-companheira que está afastada há muitos anos do mercado de trabalho, e que tem evidente dependência econômica, inclusive com reconhecimento expresso disso no contrato particular de união estável firmado entre as partes. De rigor a fixação de alimentos em prol dela. Adequado o valor fixado a título de alimentos em prol do filho comum, porquanto não comprovada a alegada impossibilidade econômica do alimentante, que inclusive apresenta evidentes sinais exteriores de riqueza. APELO DO RÉU DESPROVIDO. APELO DA AUTORA PROVIDO. EM MONOCRÁTICA. (Apelação Cível $N^{o}$ 70039284542, Oitava Câmara Cível, Tribunal de Justiça do RS, Relator: Rui Portanova, Julgado em 23/12/2010).

\section{TRIBUNAL: TJMG}

Favorável: DIREITO DAS FAMÍLIAS. UNIÃO ESTÁVEL CONTEMPORÂNEA A CASAMENTO. UNIÃO DÚPLICE. POSSIBILIDADE DE RECONHECIMENTO FACE ÀS PECULIARIDADES DO CASO. RECURSO PARCIALMENTE PROVIDO. Ao longo de vinte e cinco anos, a apelante e o apelado mantiveram um relacionamento afetivo, que possibilitou o nascimento de três filhos. Nesse período de convivência afetiva - pública, contínua e duradoura - um cuidou do outro, amorosamente, emocionalmente, materialmente, fisicamente e sexualmente. Durante esses anos, amaram, sofreram, brigaram, reconciliaram, choraram, riram, cresceram, evoluíram, criaram os filhos e cuidaram dos netos. Tais fatos comprovam a concreta disposição do casal para construir um lar com um subjetivo ânimo de permanência que o tempo objetivamente confirma. Isso é família. O que no caso é polêmico é o fato de o apelado, à época dos fatos, estar casado civilmente. Há, ainda, dificuldade de o Poder Judiciário lidar com a existência de 
uniões dúplices. Há muito moralismo, conservadorismo e preconceito em matéria de Direito de Família. No caso dos autos, a apelada, além de compartilhar o leito com o apelado, também compartilhou a vida em todos os seus aspectos. Ela não é concubina - palavra preconceituosa - mas companheira. Por tal razão, possui direito a reclamar pelo fim da união estável. Entender o contrário é estabelecer um retrocesso em relação a lentas e sofridas conquistas da mulher para ser tratada como sujeito de igualdade jurídica e de igualdade social. Negar a existência de união estável, quando um dos companheiros é casado, é solução fácil. Mantémse ao desamparo do Direito, na clandestinidade, o que parte da sociedade prefere esconder. Como se uma suposta invisibilidade fosse capaz de negar a existência de um fato social que sempre aconteceu, acontece e continuará acontecendo. A solução para tais uniões está em reconhecer que ela gera efeitos jurídicos, de forma a evitar irresponsabilidades e o enriquecimento ilícito de um companheiro em desfavor do outro. DERAM PROVIMENTO PARCIAL. Há, ainda, dificuldade de o Poder Judiciário lidar com a existência de uniões dúplices. Há muito moralismo, conservadorismo e preconceito em matéria de Direito de Família. No caso dos autos, a apelada, além de compartilhar o leito com o apelado, também compartilhou a vida em todos os seus aspectos. Ela não é concubina - palavra preconceituosa - mas companheira. Por tal razão, possui direito a reclamar pelo fim da união estável. Entender o contrário é estabelecer um retrocesso em relação a lentas e sofridas conquistas da mulher para ser tratada como sujeito de igualdade jurídica e de igualdade social. Negar a existência de união estável, quando um dos companheiros é casado, é solução fácil. Mantém-se ao desamparo do Direito, na clandestinidade, o que parte da sociedade prefere esconder. Como se uma suposta invisibilidade fosse capaz de negar a existência de um fato social que sempre aconteceu, acontece e continuará acontecendo. A solução para tais uniões está em reconhecer que ela gera efeitos jurídicos, de forma a evitar irresponsabilidades e o enriquecimento ilícito de um companheiro em desfavor do outro. DERAM PROVIMENTO PARCIAL.

(TJMG, Apelação Cível no 1.0017.05.016882-6/003, Rel ${ }^{a}$. Des. ${ }^{a}$ Maria Elza, public. 10/12/2008).

Desfavorável: DIREITO DE FAMÍLIA. RELACIONAMENTOAFETIVO PARALELO AO CASAMENTO. IMPOSSIBILIDADE DE RECONHECIMENTO DE UNIÃO ESTÁVEL. PRINCÍPIO DA MONOGAMIA. RECURSO 
NÃO-PROVIDO. O relacionamento afetivo da apelante com o seu amado não se enquadra no conceito de união estável, visto que o princípio da monogamia, que rege as relações afetivas familiares, impede o reconhecimento jurídico de um relacionamento afetivo paralelo ao casamento. Neste contexto, por se encontrar ausente elemento essencial para a constituição da união estável, qual seja, ausência de impedimento matrimonial entre os companheiros, e como o pai dos apelados não se encontrava separado de fato ou judicialmente, conforme restou suficientemente demonstrado nos autos, não é possível se caracterizar o concubinato existente como uma união estável. Entender o contrário seria vulgarizar e distorcer o conceito de união estável, instituto jurídico que foi consagrado pela Constituição Federal de 1988 com a finalidade de proteger relacionamentos constituídos com fito familiar e, ainda, viabilizar a bigamia, já que é possível a conversão da união estável em casamento. Por fim, ainda que haja no Superior Tribunal de Justiça um precedente extremamente eloqüente e em tudo assemelhado ao caso que se examina, que consiste no REsp $n^{\circ}$ 742.685, do STJ, julgado em 04-08-2005, de que foi Relator o Min. José Arnaldo da Fonseca, da $5^{\mathrm{a}}$ Turma do STJ, admitindo o direito à pensão previdenciária, deixo de apreciar o tema, visto que tal pleito há de ser formulado perante a Justiça Federal, visto que A.B.M., era Policial Rodoviário Federal, o que impede, por absoluta incompetência (artigo 109, inciso I, da Constituição da República), à Justiça Estadual reconhecer eventual direito previdenciário por parte da apelante.Negaram provimento

(TJMG, Apelação Cível no 1.0024.07.690802-9/001, Rel ${ }^{\mathrm{a}}$ Des. $^{\mathrm{a}}$ Maria $^{\circ}$ Elza, Public. 21/01/2009).

\section{TRIBUNAL: TJSP}

Favorável: Ementa: União estável. Reconhecimento e dissolução. O fato de manter dupla união não se constitui num Bill de indenidade àquele que age de forma a manter um dos companheiros na ignorância de sua atitude. Partilha dos bens adquiridos na constância da relação. Sentença reformada. Recurso provido.

(TJSP, Apelação Cível n. 646037.4/4-00, Rel. Des. Caetano Lagrasta, j. 16/12/2009).

Desfavorável: Ementa: União estável - Falecido casado - Concubinato impuro Existência de impedimento entre os litigantes que afasta a possibilidade 
de reconhecimento da união estável entre eles - Recurso provido. (TJSP, Apelação com Revisão 4073094200, Rel. Des. José Luiz Gavião de Almeida, j. 23/05/2006)

\section{TRIBUNAL: TJSP}

Favorável: Ementa: União Estável putativa. Reconhecimento. Convivente casado. Prova documental e testemunhal no sentido de que o autor estava separado de fato, mas mantinha convivência esporádica com a esposa. Sentença de procedência mantida, com determinações. Recurso improvido.

(TJSP, Apelação Cível com Revisão nº 6342814400, Rel. Des. Caetano Lagrasta, j. 03/06/2009)

\section{TRIBUNAL: TJRJ}

Favorável: UNIÃO ESTÁVEL. DISPUTA ENTRE DUAS COMPANHEIRAS. SITUACAO PUTATIVA. PROVA ORAL. RECONHECIMENTO. Reconhecimento de união estável. Conviventes, uma desde 1978 e outra desde 1960 que mantiveram relações concomitantes, notórias e ininterruptas com o de cujus, até o seu falecimento. Prova oral que confirma o reconhecimento do companheirismo concomitante com ambas perante parcelas distintas da sociedade pela qual transitava o falecido, tendo elas vivido em affectio maritalis com o de cujus, cada qual a sua forma. Pessoas de boa índole e bem intencionadas que firmemente acreditavam na inexistência de uma relação amorosa intensa do obituado com a outra, havendo êxito deste em ludibriá-las por longos anos, e de se reconhecer a existência de união estável putativa com a apelante e com a apelada. Aplicação, por analogia do art. 221 do CC de 1916. Desprovimento do recurso.

(TJRJ, Agravo:15225/2005, $2^{a}$ Câmara Civil, j.10/08/2005, relatora Des. Leila Maria Carrilo Cavalcante Ribeiro Mariano)

\section{TRIBUNAL: STJ}

Favorável: RECURSO ESPECIAL. PENSÃO PREVIDENCIÁRIA. PARTILHA DA PENSÃO ENTRE A VIÚVA E A CONCUBINA. COEXISTÊNCIA DE VÍNCULO CONJUGAL E A NÃO SEPARAÇÃO DE FATO DA ESPOSA. CONCUBINATO IMPURO DE LONGA DURAÇÃO.

"Circunstâncias especiais reconhecidas em juízo". Possibilidade de geração de direitos e obrigações, máxime, no plano da assistência social. Acórdão recorrido não deliberou à luz dos preceitos legais invocados. 
Recurso especial não conhecido.

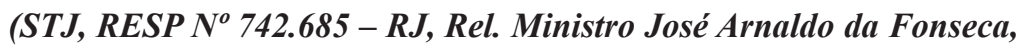
public. 05/09/2005).

Desfavorável: AGRAVO REGIMENTAL. AGRAVO DE INSTRUMENTO. DIREITO DE FAMÍLIA. DIVERGÊNCIA JURISPRUDENCIAL. AUSÊNCIA DE COMPROVAÇÃO. CONCUBINATO E UNIÃO ESTÁVEL. CARACTERIZAÇÃO. DIFERENÇA DE INSTITUTOS E EFEITOS JURÍDICOS. PARTILHA DE BENS. ESFORÇO COMUM. NECESSIDADEDE REEXAMEDEPROVAS. INADMISSIBILIDADE. SÚMULA 07/STJ.

1. Não há falar em comprovação do dissídio pretoriano, na forma exigida pelos arts. 541, parágrafo único, do $\mathrm{CPC}$ e $255, \S \S 1^{\circ}$ e $2^{\circ}$, do RISTJ, quando ausente a similitude fática entre os acórdãos confrontados.

2. Esta Corte Superior consagrou o entendimento de que a relação concubinária, paralela a casamento válido, não pode ser reconhecida como união estável, salvo se configurada separação de fato ou judicial entre os cônjuges.

3. O Supremo Tribunal Federal e o Superior Tribunal de Justiça possuem jurisprudência firmada na vertente de ser descabido o compartilhamento da pensão por morte entre a viúva e a concubina, uma vez que a pensão previdenciária somente é devida quando configurada a relação matrimonial ou a união estável, sendo inadmissível quando se tratar de concubinato.

4. Se o Tribunal de origem, com base no acervo fático e probatório dos autos, consignou que a concubina não logrou comprovar sua efetiva colaboração para a construção do patrimônio do de cujus, pelo que, ainda que se considerasse eventual sociedade de fato, não haveria bem a partilhar, chegar à conclusão diversa - no sentido da ocorrência de esforço comum -, demandaria o reexame de fatos e provas, o que é vedado na via especial, a teor da Súmula 07 do STJ.

5. Aferir se os bens doados à concubina estavam abrangidos ou não pela comunhão universal é procedimento que encontra óbice na Súmula 07 do STJ, por demandar reexame dos elementos de fato e de prova dos autos. 6. Agravo regimental a que se nega provimento.

(STJ, AgRg no Ag 683975 / RS, Rela Mini. Vasco Della Giustina, Desembargador convocado do TJ/RS, Public. DJe 02/09/2009). 


\section{TRIBUNAL: STJ}

Desfavorável: DIREITO CIVIL. FAMÍLIA. PARALELISMO DE UNIÕES AFETIVAS. RECURSO ESPECIAL. AÇÕES DE RECONHECIMENTO DE UNIÕES ESTÁVEIS CONCOMITANTES. CASAMENTO VÁLIDO DISSOLVIDO. PECULIARIDADES.

As uniões afetivas plúrimas, múltiplas, simultâneas e paralelas têm ornado o cenário fático dos processos de família, com os mais inusitados arranjos, entre eles, aqueles em que um sujeito direciona seu afeto para um, dois, ou mais outros sujeitos, formando núcleos distintos e concomitantes, muitas vezes colidentes em seus interesses. - Ao analisar as lides que apresentam paralelismo afetivo, deve o juiz, atento às peculiaridades multifacetadas apresentadas em cada caso, decidir com base na dignidade da pessoa humana, na solidariedade, na afetividade, na busca da felicidade, na liberdade, na igualdade, bem assim, com redobrada atenção ao primado da monogamia, com os pés fincados no princípio da eticidade.

$[\ldots]$

A relação mantida entre o falecido e S. M. de L. C., despida dos requisitos caracterizadores da união estável, poderá ser reconhecida como sociedade de fato, acaso deduzido pedido em processo diverso, para que o Poder Judiciário não deite em solo infértil relacionamentos que efetivamente existem no cenário dinâmico e fluido dessa nossa atual sociedade volátil. Virar as costas para os desdobramentos familiares, em suas infinitas incursões, em que núcleos afetivos se justapõem, em relações paralelas, concomitantes e simultâneas, seria o mesmo que deixar de julgar com base na ausência de lei específica. Dessa forma, na hipótese de eventual interesse na partilha de bens deixados pelo falecido, deverá S. M. de L. C. fazer prova, em processo diverso, de eventual esforço comum. Por fim, merece atenção o fato de que o autor de conduta reprovável, M. da C. G., já falecido, é quem deveria suportar as penalidades pelo comportamento afetivo paralelo, e não a concubina, que, muito embora detivesse conhecimento da vida dúplice que ele ostentava, não logrou êxito em comprovar o direito subjetivo pretendido, nos termos da legislação vigente. Considerada a imutabilidade, na via especial, da base fática tal como estabelecida no acórdão recorrido, em que consta, expressamente, o paralelismo das relações mantidas pelo falecido com a recorrente e a ex-mulher, deve ser reformado o julgado, para que se mantenha apenas o reconhecimento da união estável havida entre M. da C. G. com D. A. de O., desde 1994 até o seu óbito. Forte nessas razões, DOU PROVIMENTO 
ao recurso especial, para declarar o reconhecimento da união estável mantida entre D. A. de O. e M. da C. G. e determinar, por conseguinte, o pagamento da pensão por morte em favor unicamente da recorrente, companheira do falecido.

(STJ, Recurso Especial $n^{\circ}$ 1.157.273 - RN, Relatora Ministra Nancy Andrighi, J. 18.05.2010).

\section{TRIBUNAL: STJ}

Desfavorável: DIREITODEFAMÍLIA.RECONHECIMENTODEUNIÕESESTÁVEIS SIMULTÂNEAS. IMPOSSIBILIDADE. EXCLUSIVIDADE DE RELACIONAMENTO SÓLIDO. CONDIÇÃO DE EXISTÊNCIA JURÍDICA DA UNIÃO ESTÁVEL. EXEGESE DO $\S 1^{\circ}$ DO ART. 1.723 DO CÓDIGO CIVIL DE 2002.

1. Para a existência jurídica da união estável, extrai-se, da exegese do $\S 1^{\circ}$ do art. 1.723 do Código Civil de 2002, fine, o requisito da exclusividade de relacionamento sólido. Isso porque, nem mesmo a existência de casamento válido se apresenta como impedimento suficiente ao reconhecimento da união estável, desde que haja separação de fato, circunstância que erige a existência de outra relação afetiva factual ao degrau de óbice proeminente à nova união estável.

2. Com efeito, a pedra de toque para o aperfeiçoamento da união estável não está na inexistência de vínculo matrimonial, mas, a toda evidência, na inexistência de relacionamento de fato duradouro, concorrentemente àquele que se pretende proteção jurídica, daí porque se mostra inviável o reconhecimento de uniões estáveis simultâneas.

3. Havendo sentença transitada em julgado a reconhecer a união estável entre o falecido e sua companheira em determinado período, descabe o reconhecimento de outra união estável, simultânea àquela, com pessoa diversa.

4. Recurso especial provido.

(STJ, Resp nº 912926 / RS, Rel Min. Luis Felipe Salomão, 4ª turma, pub. 07/06/2011).

\section{TRIBUNAL: STJ}

Desfavorável: PROCESSUAL CIVIL E CIVIL. AGRAVO REGIMENTAL. FAMÍLIA. UNIÃO ESTÁVEL. RELACIONAMENTOS CONCOMITANTES. IMPOSSIBILIDADE DE CONFIGURAÇÃO. PRECEDENTES. AGRAVO REGIMENTAL IMPROVIDO. 
(STJ, AR AgRg no Ag 1358319 / DF, Rel Min. Luis Felipe Salomão, $4^{\text {a }}$ turma, pub. 11/02/2011)

\section{TRIBUNAL: STJ}

Favorável: $\quad$ OBSERVACÃO : é curioso verificar que esse acórdão ao lado, na coluna das decisões desfavoráveis, reviu a decisão do TJRJ que, por sua vez, assim havia decidido, favoravelmente:

Espólio de J. N. de S. - representado por sua inventariante R. de M. S.-e outro interpõem recurso especial, com fundamento na alínea "a" do permissivo constitucional, contra acórdão da Décima Oitava Câmara Cível do Tribunal de Justiça do Estado do Rio de Janeiro, assim ementado: "UNIÃO ESTÁVEL PUTATIVA. Sua possibilidade, se a companheira desconhece que seu companheiro mantém vida dupla e se relaciona com outra mulher anterior e com ela mantém a vida marital, sem desfazêla, para estabelecer a união posterior com exclusividade. Aplicação por analogia do art. 221 do Código Civil de 1916. Prova dos autos a denotar, que o finado mantinha união concomitante com duas mulheres, a ensejar o reconhecimento da união estável, com os efeitos jurídicos daí decorrentes, em favor das duas. Recurso provido" (fl. 246).

Desfavorável: União estável. Reconhecimento de duas uniões concomitantes. Equiparação ao casamento putativo. Lei n. 9.728/96. 1. Mantendo o autor da herança união estável com uma mulher, o posterior relacionamento com outra, sem que se haja desvinculado da primeira, com quem continuou a viver como se fossem marido e mulher, não há como configurar união estável concomitante, incabível a equiparação ao casamento putativo.

2. Recurso especial conhecido e provido.

(STJ, REsp $\mathrm{n}^{\circ} \mathrm{N}^{o} 789.293$ - RJ, Rel. Mini. Carlos Alberto Menezes Direito, j. 16/02/2006).

\section{TRIBUNAL: STF}

Favorável: (...) 'Companheiro’ como situação jurídica- ativa de quem mantinha com o segurado falecido uma relação doméstica de franca estabilidade ("união estável"). Sem essa palavra azeda, feia, discriminadora, preconceituosa, do concubinato. Estou a dizer: não há concubinos para a Lei Mais Alta do nosso País, porém casais em situação de companheirismo. Até porque o concubinato implicaria discriminar os eventuais filhos do casal, que passariam a ser rotulados de "filhos concubinários". Designação pejorativa, 
essa, incontornavelmente agressora do enunciado constitucional de que “os filhos, havidos ou não da relação do casamento, ou por adoção, terão os mesmos direitos e qualificações, proibidas quaisquer designações discriminatórias relativas à filiação. (...) A concreta disposição do casal para construir um lar com um subjetivo ânimo de permanência que o tempo objetivamente confirma. Isto é família, pouco importando se um dos parceiros mantém uma concomitante relação sentimental a-dois. No que andou bem a nossa Lei Maior, ajuízo, pois ao direito não é dado sentir ciúmes pela parte supostamente traída, sabido que esse órgão chamado coração 'é terra que ninguém nunca pisou'. Ele, coração humano, a se integrar num contexto empírico da mais entranhada privacidade, perante o qual o Ordenamento Jurídico somente pode atuar como instância protetiva. Não censora ou por qualquer modo embaraçante (...)

(STF, REx. 397.762-8 BA; Rel. Min. Marco Aurélio; Trecho do votovista do min. Carlos Ayres Britto; public. DJE de 12-9-08.)

Desfavorável: Companheira e concubina. Distinção. Sendo o Direito uma verdadeira ciência, impossível é confundir institutos, expressões e vocábulos, sob pena de prevalecer a babel. (...) A proteção do Estado à união estável alcança apenas as situações legítimas e nestas não está incluído o concubinato. (...) A titularidade da pensão decorrente do falecimento de servidor público pressupõe vínculo agasalhado pelo ordenamento jurídico, mostrando-se impróprio o implemento de divisão a beneficiar, em detrimento da família, a concubina."

(STF, RE 590.779, Rel. Min. Marco Aurélio, julgamento em 10-2-09, $1^{a}$ Turma, DJE de 27-3-09)

São Paulo, junho de 2013. 